INVESTIGATION OF THE MOVEMENT OF A SAPROPEL PARTICLE IN A FINAL INTAKE PART OF A SCREW MECHANISM

\author{
V. Bodak ${ }^{1}$, G. Hailis ${ }^{2}$, O. Dubytskyi ${ }^{1}$, P. Mazyliuk ${ }^{1}$ \\ ${ }^{1}$ Lutsk National Technical University, Lutsk, Ukraine \\ ${ }^{2}$ Uman National University of Horticulture, Uman, Ukraine
}

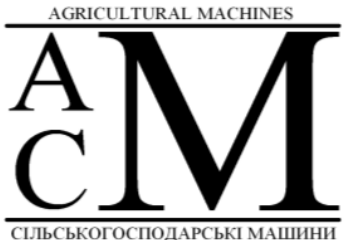

Key words:

sapropel,

auger,

sapropel extraction,

conical intake,

blade

Article history:

Received 03.03.2020

Accepted 28.05.2020

Corresponding author:

Bodak.lutsk@gmail.com
ABSTRACT

The article proposes the design of a mechanism for the extraction of sapropels in small and shallow water bodies. The mechanism allows not to dilute sapropel with water and to lift deposits of natural moisture from the bottom of the reservoir. This mechanism is easy to manufacture and operate, much cheaper than analogues, reliable in operation, mobile. Extraction of sapropels by the proposed mechanism improves the environmental performance at the extraction site, as it has a low siltation rate. To develop the design of the intake part of the mechanism, the motion of the sapropel particle during its interaction with the auger blade was analyzed. The dependences for determining the trajectory of sapropel particles in the intake part of the screw pump are theoretically derived. It is proposed to design the screw of the intake part of the mechanism so as to alternately place the intermittent blades with positive and negative values of the angle of inclination of the blade to the plane perpendicular to the axis of rotation of the auger. This will allow more intensive grinding of the compacted lower layer of sapropel. It is determined that the height of the conical intake part should be 2...3 times greater than the height of the screw. In this case, the sapropel particle will not be able to bounce off the blade and out of the conical part.

https://doi.org/10.36910/agromash.vi44.308 
УДК 631.826

\title{
ДОСЛІДЖЕННЯ РУХУ ЧАСТИНКИ САПРОПЕЛЮ В КОНІЧНІЙ ЗАБІРНІЙ ЧАСТИНІ ШНЕКОВОГО МЕХАНІЗМУ
}

\author{
В.І. Бодак ${ }^{1}$, Г.А. Хайліс ${ }^{2}$, О.С. Дубицький ${ }^{1}$ П.В. Мазилюк ${ }^{1}$ \\ ${ }^{1}$ Луцький національний технічний університет, Луцьк, Україна \\ ${ }^{2}$ Уманський національний університет садівництва, Умань, Україна
}

У статті запропонована конструкиія механізму для добування сапропелів на малих площах та мілководних водоймах. Механізм дає змогу не розбавляти сапропель водою та піднімати із дна водойми поклади природної вологості. Цей механізм є простим у виготовленні та експлуатації, його вартість значно менша від аналогів, також механізм є надійним в роботі та мобільним. Добування сапропелів запропонованим механізмом покрамує екологічні показники на місиі добування, оскільки має низький коефіиієнт змулювання. Для розробки конструкиї забірної частини механізму було проаналізовано рух частинки сапропелю при взаємодії ї̈ із лопаттю шнека. Теоретично виведено залежності для визначення траєкторії руху частинок сапропелю в забірній частині шнекового насоса. Запропоновано гвинт забірної частини механізму конструювати таким чином, щоб почергово розмімувати перервні лопаті з додатнім та від'ємним значенням кута нахилу лопаті до площини, яка перпендикулярна осі обертання шнека. Це дозволить більш інтенсивно подрібнювати злежаний нижній шар сапропелю. Визначено, що висота конічної забірної частини повинна бути в 2 ...3 рази більшою за висоту гвинта забірної частини. У такому випадку частинка сапропелю не зможе відбитися від лопаті та вийти із конічної частини, $i$, відповідно, не буде проходити процес змулювання в зоні добування.

Ключові слова: сапропель, инек, добування сапропелю, конічна забірна частина, лопать.

\section{Стан питання та постановка проблеми}

Машини, які використовуються для добування сапропелів малоефективні, оскільки мають низькі екологічні показники внаслідок непристосованості до піднімання із дна водойм дрібнодисперсних речовин. Повільно впроваджуються машини, які можуть працювати на невеликих за площею або мілководних водоймах без їх осушення [1]. На сьогодні дорого купувати земснаряди, екскаватори-грейфери, будувати набережні споруди (причали, відстійники). Створені шнекові 
механізми для добування сапропелів також мають низку конструктивних недоліків [2].

Мета дослідження - провести дослідження процесу добування сапропелів шнековим механізмом із різнонапрямленими лопатями у забірній частині, які б забезпечували розрихлення злежаних нижніх шарів покладів.

\section{Матеріали і методи}

Для математичного опису процесу переміщення частинки сапропелю застосовували методи диференціальної геометрії, класичної механіки, лінійної алгебри та гідравліки. Теоретичні розрахунки перевірялись під час проведення експериментальних досліджень. Також під час дослідження визначалися характеристики механізму для добування сапропелів.

\section{Результати дослідження та обговорення}

Одним із перспективних для добування сапропелів на мілководних та малих за площею водоймах є механізм, що представлений на рис. 1.

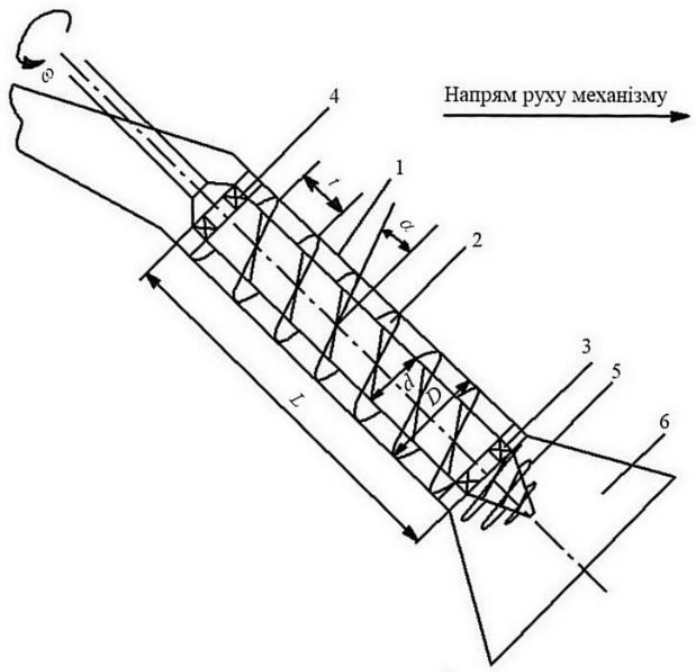

Рис. 1 - Механізм для добування сапропелів:

1 - кожух; 2 -шнек; 3, 4- підшипники; 5 - конічний гвинт; 6 - забірна конічна частина

Механізм для добування сапропелів, що виконаний у вигляді гвинтового конвеєра, містить кожух, в якому може обертатися шнек 
циліндричної форми. У забірній частині шнек закінчується конічним гвинтом [3, 4]. При обертанні лопаті конічного гвинта подрібнюють масу частинок сапропелю та спрямовують їх вверх. На частинки сапропелю та води діють поперечні складові сил тиску 3 боку гвинтових лопатей циліндричної частини гвинта, а також складові сили їх тертя по лопаті. Виникаючий момент сили тяжіння частинок та води відносно осі гвинта перешкоджає подальшому обертальному руху переміщуваних частинок, у результаті останні будуть переміщатися вздовж осі конвеєра в напрямку транспортування [5].

У конічній частині механізму проходить подрібнення злежаного шару сапропелю та його волокнистих включень, перемішування частинок шару і їх спрямування вверх, де відбувається їх захоплення лопатями шнека. Розглянемо роботу лопатей конічної частини механізму.

На рис. 2 показана плоска лопать, що обертається навколо похилої осі $O O^{\prime}$ із кутовою швидкістю $\omega$. При обертанні лопать діє на частинки сапропелю, в тому числі на частинку $M$. Лопать відхилена від площини, перпендикулярної до осі $O O^{\prime}$, на кут $\alpha$, а її середня лінія $O_{1} M$ перпендикулярна осі $O O^{\prime}$. Кут $\alpha \in$ незначним (кут $\alpha$ менший за $\left(90^{\circ}-\varphi\right)$, де $\varphi$ - кут тертя частинки по поверхні лопаті, град.).

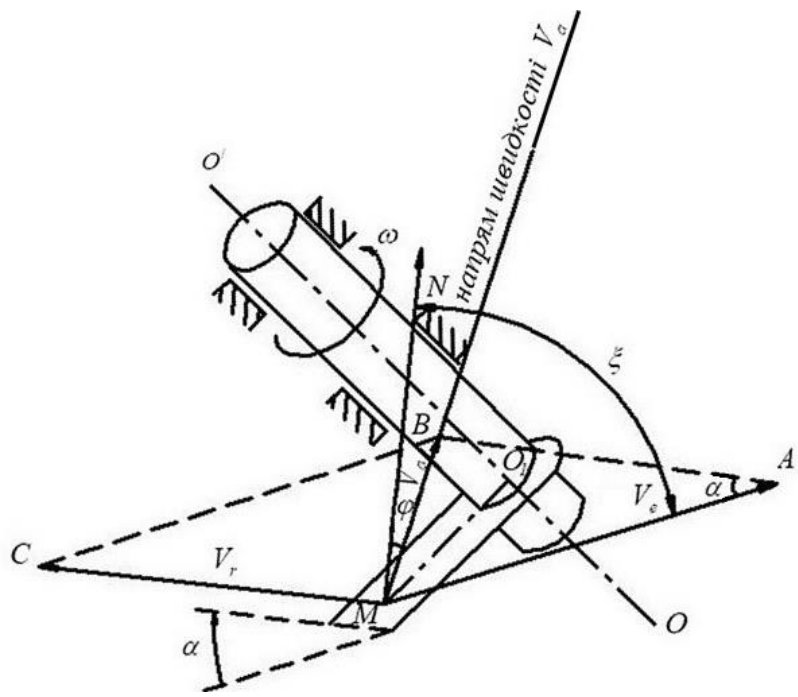

Рис. 2 - Схема до визначення швидкості частинки сапропелю при дії на неї лопаті конічної частини гвинта (у випадку $\alpha>0$ ) 
Частинка $M$ сапропелю здійснює складний рух, що складається із переносного руху разом із лопаттю і відносного руху відносно лопаті. Швидкість переносного руху $V_{e}$ рівна $\omega r$, де $r=O_{1} M-$ радіус обертання. Швидкість $V_{e}$ спрямована перпендикулярно $O_{1} M$ та знаходиться в площині, що перпендикулярна $O O^{\prime}$. Швидкість відносного руху $V_{r}$ знаходиться в площині лопаті та в площині, що паралельна осі $O O^{\prime}$ та перпендикулярна $O_{1} M$ і яка проходить через вектор $V_{e}$. Швидкість $V_{r}$ відома тільки за своїм напрямком.

Для визначення абсолютної швидкості $V_{a}$ частинки врахуємо, що лопать діє на частинки сапропелю та рідини так, як діє клин. Як відомо iз теорії клина [6], якщо кут між вектором швидкості точки клина, в якій доторкається частинка, і нормаллю до площини клина більший за кут тертя частинки по поверхні клина, то частинка буде рухатися в напрямку, відхиленому від нормалі на кут тертя $\varphi$ в сторону швидкості точки клина. Застосовуючи до лопаті дане положення, знаходимо, що частинка $M$ буде рухатись у напрямку вектора швидкості $V_{e}$, який відхилений від нормальної сили $N$ на кут $\varphi$ в сторону швидкості $V_{e}$, якщо кут $\xi$ між векторами $N$ i $V_{e}$ більший за кут $\varphi$.

Для визначення швидкостей $V_{r}$ та $V_{a}$ проведемо із кінця $A$ вектора $V_{e}$ лінію, що паралельна $V_{r}$, до перетину із лінією вектора $V_{a}$. Провівши iз кінця $B$ вектора $V_{a}$ лінію, що паралельна вектору $V_{e}$, до перетину із лінією дії вектора $V_{r}$, отримаємо точку $C$.

Ураховуючи, що вектор $N$ знаходиться в площині $M A B C$, знаходимо, що кут між швидкостями $V_{e}$ та $V_{a}$ рівний $(\xi-\varphi)$ (де значення кута $\left.\xi=\left(90^{\circ}-\alpha\right) ; \angle \mathrm{MAB}=\alpha ; A B=M C ; B C=M A\right)$. Ураховуючи викладене, справедлива рівність:

$$
\frac{V_{e}}{\sin \left(180^{\circ}-\alpha-(\xi-\varphi)\right)}=\frac{V_{r}}{\sin (\xi-\varphi)}=\frac{V_{a}}{\sin \alpha} .
$$

Звідки, із урахуванням того, що:

$$
\left.\begin{array}{c}
V_{e}=\omega \cdot r ; \\
V_{r}=\omega \cdot r \frac{\cos (\alpha-\varphi)}{\cos \varphi} ;
\end{array}\right\}
$$

Залежності (1) - (3) справедливі за умови $\alpha<\left(90^{\circ}-\varphi\right)$. Кут $\alpha$ при цьому відраховується від площини, яка перпендикулярна до осі $O O^{\prime}$, в сторону кінця $O^{\prime}$ вказаної осі. У цьому напрямку кут $\alpha$ буде зі знаком “+”. Якщо ж лопать відхилена від площини, що перпендикулярна осі $O O^{\prime}$, так, що кут відраховується в сторону кінця $O$ осі $O O^{\prime}$ (рис. 3), то 
кут $\alpha$ буде зі знаком “-”, від’ємним буде і значення швидкості $V_{a}$ згідно формули (3). Це означає, що швидкість буде спрямована не в сторону кінця $O^{\prime}$ осі $O O^{\prime}$, а в сторону кінця $O$ осі $O O^{\prime}$.

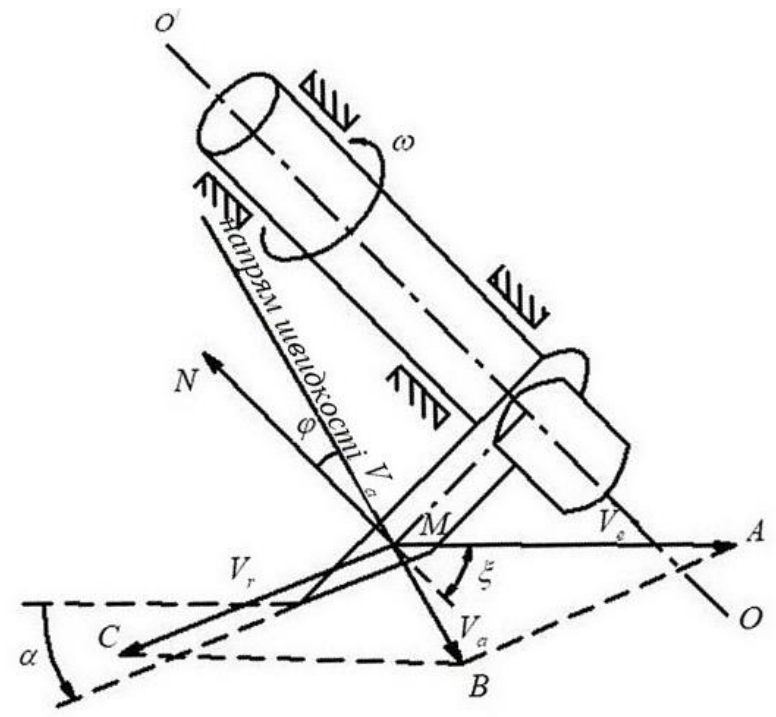

Рис. 3 - Схема до визначення швидкості частинки сапропелю при дії на неї лопаті конічної частини гвинта (у випадку $\alpha<0)$

Ураховуючи викладене, необхідно гвинт забірної частини розглядуваного механізму конструювати таким чином, щоб почергово розміщувати перервні лопаті із додатнім та від'ємним значенням кута $\alpha$. Це дозволить більш інтенсивно подрібнювати злежаний нижній шар сапропелю та перемішувати його частинки.

Було розглянуто дію лопаті на окрему частинку сапропелю. У дійсності, кожна лопать працює в рідкому середовищі та діє не на одну частинку, а на весь шар сапропелю і води. При цьому, кожна частинка сапропелю досягаючи швидкості $V_{a}$, рухається в рідині, долаючи її опір. Під час подолання опору, енергія частинки гаситься, а iіi швидкість зменшується [7]. Розглянемо цей процес.

На рис. 4 показано частинку $M$, яка рухається в рідині із початкового положення $M_{0}$ на висоті $H$ від дна озера із початковою швидкістю $V_{a}$. На частинку діє сила тяжіння $m g$ (де $m$ - маса частинки, кг; $g$ - прискорення вільного падіння, м/ $\mathrm{c}^{2}$ ) і сила опору середовища $R$. 
Нехай, сила $R$ прямопропорційна масі частинки і її швидкості в першій степені, тобто:

$$
R=-k m V,
$$

де $V$ - швидкість руху частинки, м/с; $k$ - коефіцієнт опору, постійний за величиною для певної в'язкості розроблюваної маси (визначається дослідним шляхом).

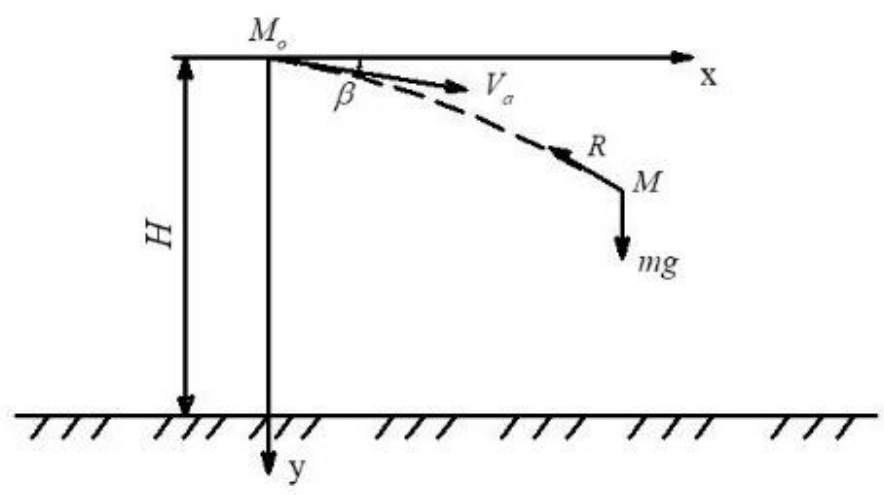

Рис. 4 - Схема руху частинки сапропелю в рідині

Розташуємо початок координат в точці $M_{0}$, вісь $y$ спрямуємо від точки $M_{0}$ вниз, а вісь $x$ спрямуємо горизонтально. Складемо векторне диференційне рівняння руху частинки:

$$
m \bar{w}=m \bar{g}+\bar{R},
$$

де $\bar{w}-$ вектор прискорення частинки.

Вектори прискорення частинки та сили $R$ :

$$
\begin{gathered}
\bar{w}=\overline{\ddot{r}}, \\
\bar{R}=-k \cdot m \cdot \bar{V}=\bar{k} \cdot m \cdot \overline{\dot{r}},
\end{gathered}
$$

де $\bar{r}$ - радіус-вектор точки $M$; $\overline{\dot{r}}$ - перша похідна від $r$ за часом (вектор швидкості); $\overline{\ddot{r}}$ - друга похідна за часом (вектор прискорення).

Після скорочення на $m$, отримаємо:

$$
\overline{\ddot{r}}=\bar{g}-k \cdot \overline{\dot{r}} \text {. }
$$

Проєктуючи рівняння (8) на осі $x$ і $y$, отримаємо диференційне рівняння руху частинки:

$$
\left.\begin{array}{l}
\ddot{x}=-k \cdot \dot{x} ; \\
\ddot{y}=g-k \dot{y},
\end{array}\right\}
$$


де $\dot{x}, \dot{y}-$ проєкції швидкості частинки $M$ на осі координат $x$ та $y, \mathrm{~m} / \mathrm{c}$; $\ddot{x}, \ddot{y}$ - проєкції прискорення частинки $M$ на осі координат $x$ та $y, \mathrm{M} / \mathrm{c}^{2}$.

Проєкція $\ddot{x}$ рівна $d \dot{x} / d t$ (де $t$ - час, с), тоді:

$$
\frac{d \dot{x}}{d t}=-k \cdot \dot{x} \text {. }
$$

Звідки, за початкових умов $t=0, \dot{x}=V_{a} \cos \beta$ :

$$
\dot{x}=e^{-k t} V_{a} \cos \beta,
$$

де $\beta$ - кут нахилу вектора швидкості в початковий момент до осі $x$, град.

Оскільки $\dot{x}=\frac{d x}{d t}$, тоді матимемо:

$$
d x=e^{-k t} V_{a} \cos \beta \cdot d t .
$$

Після інтегрування (12) та визначення сталої інтегрування за початкових умов $t=0, x=0$, матимемо:

$$
x=\frac{V_{a} \cos \beta}{k} \cdot\left(1-e^{-k t}\right) .
$$

Для розв’язування другого рівняння системи (9) урахуємо, що:

$$
\ddot{y}=\frac{d \dot{y}}{d t} .
$$

Тоді, за початкових умов $t=0, \dot{y}=V_{a} \sin \beta$, матимемо:

$$
d y=\frac{k V_{a} \sin \beta-g}{k} \cdot e^{-k t} d t+\frac{g}{k} d t .
$$

Після інтегрування (15) та визначення сталої інтегрування за початкових умов $t=0$ і $y=0$, отримаємо:

$$
y=\frac{k V_{a} \sin \beta-g}{k^{2}} \cdot\left(1-e^{-k t}\right)+\frac{g}{k} t .
$$

Таким чином, частинка здійснює рух в прийнятій системі координат згідно рівнянь (13) та (16). Кут $\beta$ у даних рівняннях додатній, коли він відраховується від горизонталі за годинниковою стрілкою і швидкість $V_{a}$ спрямована вправо та вниз (рис. 4). Якщо ж швидкість $V_{a}$ спрямована вправо і вверх, тоді кут $\beta$ буде зі знаком “-”. Таким чином, рівняння справедливі і за додатних значень кута $\beta$, i за від'ємних значеннях цього кута.

Скористаємось отриманими рівняннями для визначення радіуса конічної камери. Якщо вісь $M_{0} y$ (рис. 4) буде співпадати із краєм лопаті гвинта, із якої сходить частинка сапропелю (рис. 5), тоді для 
задовільного перемішування частинок в камері необхідно, щоб виконувалася рівність:

$$
M_{0} k=\frac{R_{k}-r_{\lambda}}{\cos \delta},
$$

де $M_{0} k$ - відстань від точки $M_{0}$ до стінки камери, м; $R_{k}$ - радіус камери в зоні дії лопаті гвинта, м; $r_{\lambda}$ - радіус лопаті, м; $\delta$-кут відхилення осі шнека від вертикалі, град.

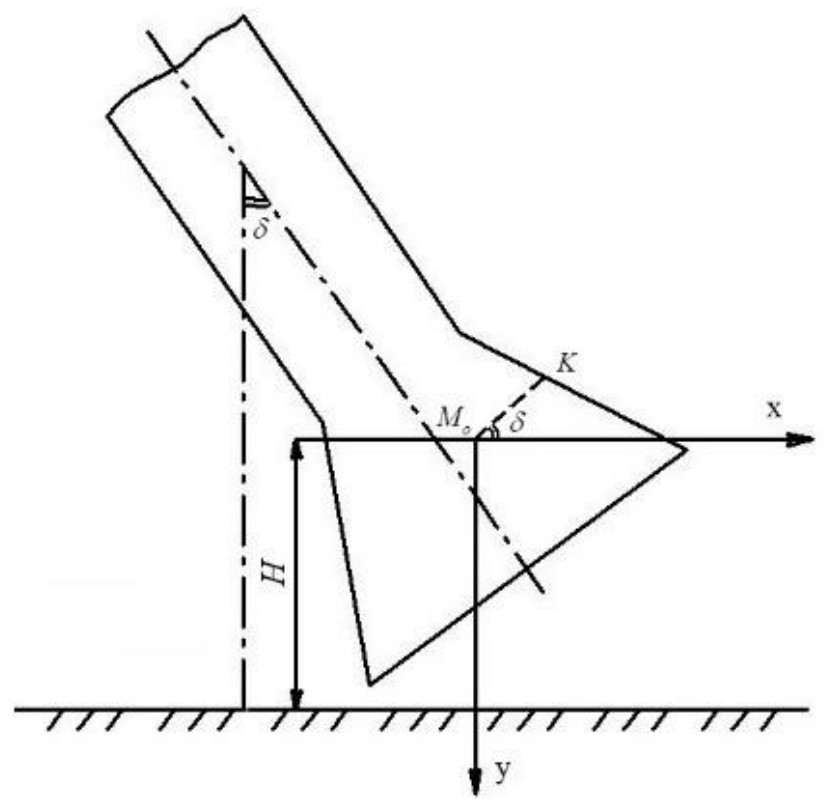

Рис. 5 - Схема до визначення параметрів конічної частини насосу

Внаслідок конусності камери, у випадку $\frac{R_{k}-r_{\lambda}}{\cos \delta}=x_{\max }$ (де $x_{\max }-$ максимальна абсциса траєкторії руху частинки від краю лопаті до стінки камери, м) можливо, що частинка не доторкнеться до стінок камери.

Ураховуючи зазначене, абсциса $x_{\max }$ має бути більшою за $\frac{R_{k}-r_{\lambda}}{\cos \delta}$. Із другого боку, внизу, в конічній частині насосу $r_{\lambda} \rightarrow 0$. Ураховуючи зазначене, та те, що за малого кута $\delta$ його косинус прямує $\cos \delta \rightarrow 1$, то приходимо до висновку, що повинна мати місце рівність: 


$$
x_{\max }=\xi_{1} R_{k},
$$

де $\xi_{1}-$ коефіцієнт, який рівний $\xi_{1}=1,2 \ldots 1,5$.

Параметр $x_{\max }$ знаходиться за рівнянням (13) при відомому часі $t$, який знаходиться шляхом розв'язування рівняння (16). Якщо в рівняння (16) замість $y$ підставити величину відстані $H$ від точки $M_{0}$ до дна озера, тоді отримаємо:

$$
R_{k}=\frac{x_{\max }}{\xi_{1}} .
$$

Висоту $h_{0}$ конічної частини гвинта вибирають таким чином, щоб вона була значно меншою за висоту конічної камери $h_{1}$, щоб забезпечити захист обертових частин від їх зіткнення із твердими предметами, а також, щоб унеможливити процес змулювання:

$$
h_{0}=\frac{h_{1}}{k_{1}} .
$$

де $k_{1}-$ коефіцієнт, який рівний $k_{1}=2 \ldots 3$.

Кут конусності встановлюється із урахуванням висоти конічної частини і діаметра шнека.

\section{Висновки}

Процес добування сапропелів на малих за площею озерах варто здійснювати шнековим механізмом із різнонапрямленими лопатями в забірній частині, щоб забезпечити розрихлення злежаних нижніх шарів покладів.

Основні параметри руху сапропелевої маси в конічній частині шнекового насосу визначаються на основі залежностей (3), (13) та (16). На основі залежності (20) рекомендовані конструктивні розміри конічної частини шнекового механізму. У відповідності до цих залежностей, забірну конічну частину механізму необхідно конструювати таким чином, щоб розрихлені частинки сапропелю не могли відбиватися від лопатей у зоні розробки та не змулювали водойму.

\section{Список посилань}

1. Дідух, В. Ф. Аналіз засобів для добування сапропелів / В. Ф. Дідух, О. П. Шимчук // Тези XXI-ої науково-технічної конференції професорсько-викладацького складу. - Луцьк, 2006. - С. 105-106.

2. Дідух, В. Ф. Дослідження добування озерного сапропелю 3-під шару води та його використання під час виробництва органічних добрив / В. Ф. Дідух, Р. А. Хлопецький, М. М. Поліщук // Сільськогосподарські машини : зб. наук. ст. - Луцьк, 2014. - Вип. 29-30. - C. 137-144. 
3. Бодак, В. І. Розробка і дослідження механізмів для добування сапропелів : дис. на здобуття наук. ступеня канд. техн. наук : спец. 05.20.01 / Бодак Володимир Іванович; Луцький індустріальний інститут. - Луцьк, 1996. - 209 с.

4. А.с. №1765311, МПК Е02 F3/88. Грунтозаборное устройство землесосного снаряда / Бодак В. И., Дидух В. Ф., Хайлис Г. А., Шевчук М. И.; Бюл. №36, 1992 р.

5. Гевко, Б. М. Винтовые подающие механизмы сельскохозяйственных машин / Б. М. Гевко, Р. М. Рогатынский. - Львов : Выща школа, 1989. - 175 с.

6. Хайліс, Г. А. Основи проектування і дослідження сільськогосподарських машин / Г. А. Хайліс, Д. М. Коновалюк. - К : НМК BO, 1992. -319 c.

7. Дідух, В. Ф. Вибір методу розрахунку процесу різання середнього шару сапропелю / В. Ф. Дідух, Р. А. Хлопецький // Сільськогосподарські машини : зб. наук. ст. - Луцьк, 2011. - Вип. 21. T. I. - C. $110-116$. 